\title{
PostScript
}

If you have a burning desire to respond to a paper published in Journal of Clinical Pathology, why not make use of our "rapid response" option?

Log on to our website (www.jclinpath.com), find the paper that interests you, and send your response via email by clicking on the "eletters" option in the box at the top right hand corner.

Providing it isn't libellous or obscene, it will be posted within seven days. You can retrieve it by clicking on "read eletters" on our homepage.

The editors will decide as before whether to also publish it in a future paper issue.

\section{A case of rapidly enlarging unilocular thymic cyst}

Thymic cysts occur relatively rarely and account for only about 3\% of all anterior mediastinal masses. ${ }^{1}$ Although thymic cysts usually grow very slowly, there have been three reported cases of unilocular thymic cysts that enlarged rapidly as a result of intracystic haemorrhage: two cases occurred in children with aplastic anaemia and one occurred in a 13 year old boy with no other symptoms. $^{23}$ Here, we present a case of a unilocular thymic cyst, which appeared within one year, was associated with chronic inflammation, and had findings different from the cases reported previously.

The patient was a 63 year old man, who had been well with no apparent symptoms of disease. There was no history of trauma. He complained of dull anterior chest pain in April 2001 , and a chest $x$ ray film showed an abnormal shadow in the left mediastinum. A chest

\section{CORRESPONDENCE}

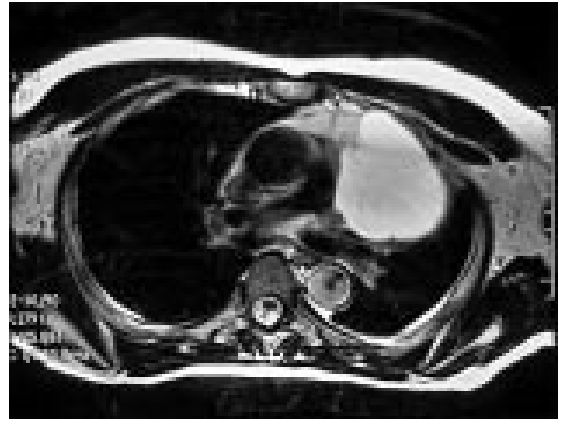

Figure 2 Magnetic resonance imaging shows a unilocular cyst $8 \times 6 \mathrm{~cm}$ in diameter at the left anterior mediastinum.

$x$ ray that had been taken one year before for a routine medical examination had shown no abnormality (fig 1). Computed tomography and magnetic resonance imaging showed unilocular cyst measuring $8 \times 6 \mathrm{~cm}$ in the left side of the anterior mediastinum (fig 2). The cyst was sharply demarcated from the mediastinal fat. Haematological and laboratory examinations showed no inflammation.

Thoracoscopic surgery, with a left thoracic approach, was conducted on 8 May 2001. The cyst originated in the thymic tissue and adhered extensively to the left upper lobe of the lung. The cyst and its neighbouring thymic tissue were resected completely.

The cyst contained a brownish fluid, the cytology of which showed numerous old red blood cells with some lymphocytes and macrophages. On gross macroscopic examination, the cyst was unilocular and the cyst wall was of varying thickness up to $5 \mathrm{~mm}$. The whole of the resected material was examined histologically by making 22 sliced sections. The cyst wall was lined mostly with cuboidal epithelium and partially with squamous epithelium, but without respiratory type epithelium. There were scattered thymic

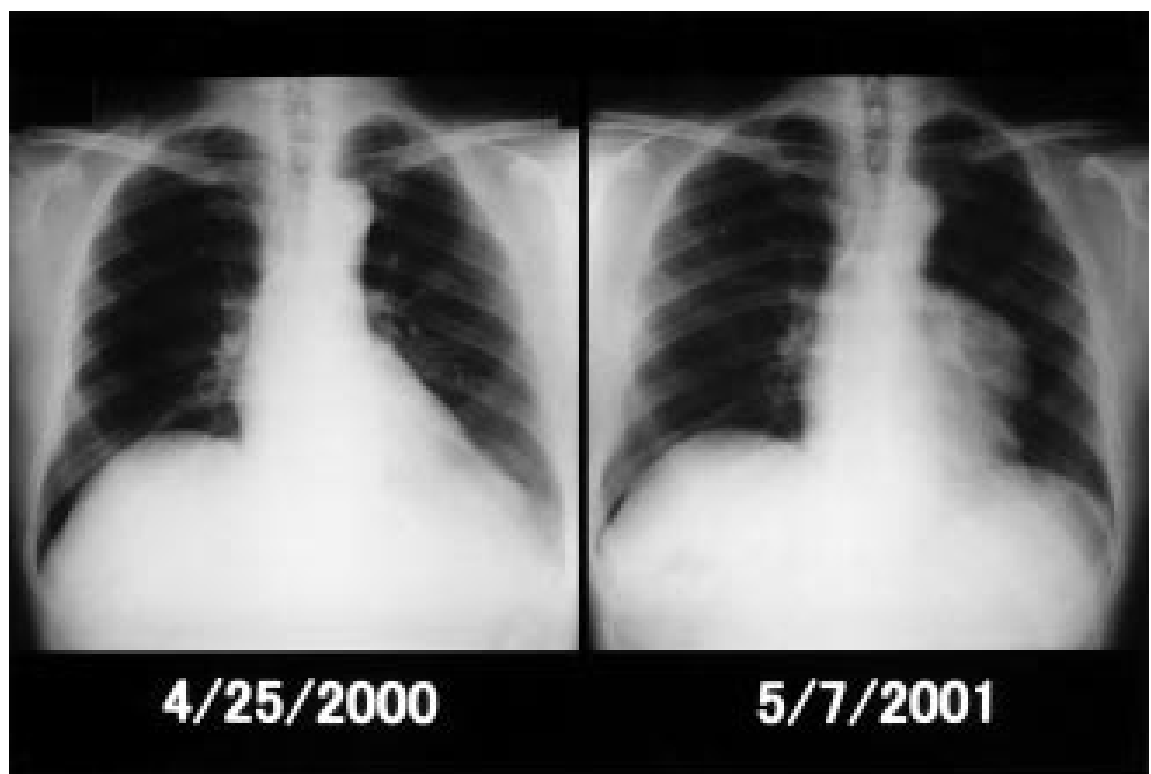

Figure 1 The chest $x$ ray film taken one year before presentation (left) shows no abnormality whereas the film taken at presentation (right) shows the abnormal shadow at the left mediastinum.

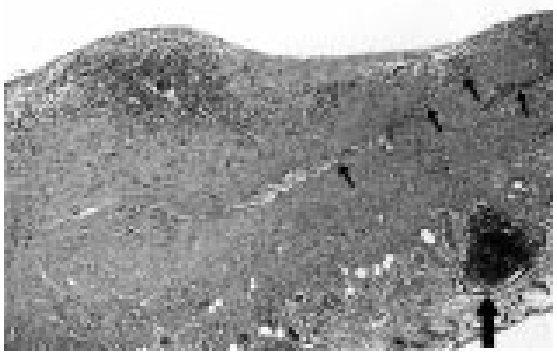

Figure 3 The wall of the cyst contains thymic tissues (large arrow) and also elongated branching strands of thymic tissues within the wall (small arrows) (haematoxylin and eosin stain; original magnification, $\times 36$ )

tissues and also elongated branching strands of thymic tissue within the wall (fig 3). Reactive lymphoid hyperplasia with a germinal centre was not seen in the thymic tissue. In most areas, the cyst wall was thickened with granulation. The granulation tissue just beneath the intraluminal wall consisted mostly of newly formed blood vessels with lymphocyte and macrophage infiltration. There were few neutrophils. Some areas of the cyst wall showed abundant deposits of haemosiderin pigments. Immunohistochemical examination using anti-CD3 and anti-CD79a antibodies showed that the infiltrating lymphocytes were a mixture of both $\mathrm{T}$ and $\mathrm{B}$ cells. There was no indication of caseous necrosis or Langhans giant cells. The patient is now doing well without recurrence of the cyst four months after surgery.

Most thymic cysts are found incidentally during chest $x$ ray or computed tomography procedures, and they usually do not enlarge in a short period. The pathogenesis of thymic cysts is currently thought to be congenital, originating from branchial pouch remnants. However, in our present case the thymic cyst was different from the congenital form because it enlarged rapidly. The cytological and histological findings were also different from those of congenital thymic cysts in the following respects: (1) the fluid within the cyst showed numerous old red blood cells with some lymphocytes and macrophages; and (2) the cyst wall showed non-specific chronic inflammation.

Although the cyst in our present case was unilocular, its pathological features were something like those of a multilocular thymic cyst (MTC), as reported by Suster and Rosai. ${ }^{4}$ They reported the clinical and pathological features of 18 cases of anterior mediastinal MTC, collected from personnel consultant files. The main histological features of the MTCs included multiple cystic cavities partially lined by squamous, columnar, or cuboidal epithelium; scattered nests of nonneoplastic thymic tissue within the cyst walls; and severe acute and chronic inflammation accompanied by fibrovascular proliferation, necrosis, haemorrhage, and granulation tissue formation. They concluded that the MTCs probably resulted from cystic transformation in the ductal epithelial formations of the branchial pouch or from a related process induced by acquired inflammation. Our present case showed pathological findings similar to those of MTC except 
that it was unilocular. We believe that, although our present case was not an MTC, it could have originated from a process similar to that leading to MTC development, and could have been enlarged by intracystic haemorrhage as a result of idiopathic, chronic inflammation.

H Nomori, H Horio, K Suemasu Department of Thoracic Surgery, Saiseikai Central Hospital, 1-4-17 Mita, Minato-ku, Tokyo 108-0073, Japan; hnomori@qk9.so-net.ne.jp

H Orikasa, K Yamazaki Department of Pathology, Saiseikai Central Hospital

K Nakano

Department of Internal Medicine, Tokyo Senbai Hospital, Tokyo, Japan

\section{References}

1 Davis RD, Jr, Oldham HN, Jr, Sabiston DC,

Jr. Primary cysts and neoplasms of the mediastinum: recent changes in clinical presentation, methods of diagnosis, management and results. Ann Thorac Surg 1987:4:229-37

2 Leibman AJ, Morehouse HT, Ziprkowski M. Spontaneous rupture of a thymic cyst demonstrated by computed tomography. $J$ Comput Assist Tomogr 1984;8:550-2.

3 Moskowitz PS, Noon MA, McAlister WH, et al. Thymic cyst hemorrhage: a cause of acute, symptomatic mediastinal widening in children with aplastic anemia. AJR Am J Roentgenol 1980:134:832-6.

4 Suster S, Rosai J. Multilocular thymic cyst: an acquired reactive process. Am I Surg Pathol 1991;15:388-98.

\section{Fatal disseminated toxoplasmosis in a toxoplasma seropositive liver transplant recipient}

Disseminated toxoplasmosis is a severe disease that occurs in immunocompromised patients but has been rarely reported after liver transplantation. We describe the first case of fatal disseminated toxoplasmosis in a toxoplasma seropositive liver transplant recipient with a documented lack of a rise in specific IgG.

A 53 year old patient underwent liver transplantation because of decompensated alcoholic cirrhosis. The patient was treated with antithymocyte globulins and prednisolone. Tacrolimus was added and antithymocyte treatment stopped. Oral ganciclovir was given to prevent cytomegalovirus infection. On day 22 , the patient developed fever with chills. Physical examination was normal and blood analysis revealed leucopenia (leucocytes, 700/ $\mathrm{mm}^{3}$ ). Blood, urine, and bile cultures were repeatedly negative. Concentrations of antibodies against aspergillus and candida did not increase. Our patient was toxoplasma seropositive before the liver transplantation (specific IgG, $15 \mathrm{IU} / \mathrm{ml}$ ) and the weekly serological follow up showed no rise in IgG titre and an absence of IgM.

Chest radiography, abdominal ultrasound, and transoesophagus ultrasonography revealed no abnormality. Ganciclovir was discontinued and leucocytes increased to 9400/ $\mathrm{mm}^{3}$. Despite broad spectrum antimicrobial treatment (ceftazidine, ciprofloxacine, teicoplanine, and fluconazole), the patient developed a diffuse bilateral interstitial pneumonitis with respiratory distress. On day 30 a bronchoalveolar lavage (BAL) was performed but no pathogens were identified. On day 36 the patient died of refractory septic shock. Necropsy revealed disseminated toxoplasmosis. Lesions were identified on haematoxylin and eosin stained sections within the heart

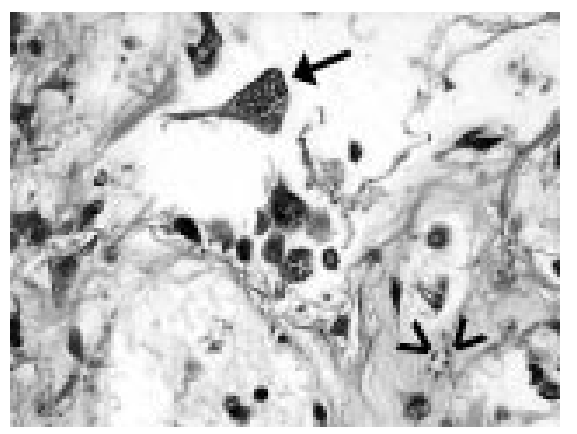

Figure 1 Toxoplasmic pneumonitis: toxoplasmic pseudocyst (arrow) and free tachyzoites (arrowheads). Haematoxylin and eosin stained.

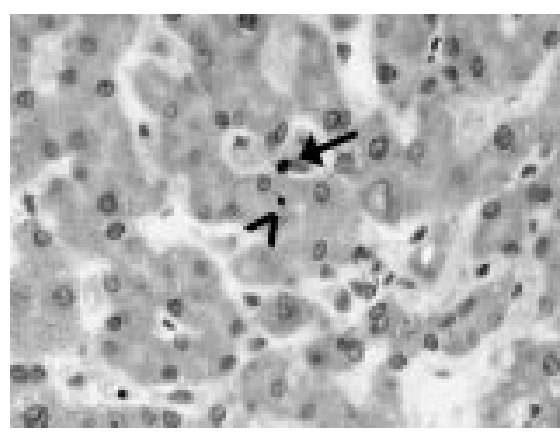

Figure 2 Liver involvement: Toxoplasma gondii in a sinusoidal cell (arrow) and in a hepatocyte (arrowhead). Toxoplasma specific immunostaining.

(pseudocysts in myocytes and foci of necrotic myocytes with free tachyzoites) and the lungs (fig 1). Tachyzoites were also identified in the liver (fig 2), kidneys (endothelial cells), pancreas (acinar cells), and spleen on immunostaining using a specific antitoxoplasma antibody (Biogenex, San Ramon, California, USA). Re-examination of the BAL revealed very rare tachyzoites.

Disseminated toxoplasmosis is a severe disease with a very high mortality rate, but treatment with pyrimethamine sulfadiazine or clindamycin can sometimes be effective. ${ }^{1}$ It occurs very rarely after liver transplantation, ${ }^{2-5}$ and can result from primary infection or reactivation, as in our patient. In addition to the heavy immunosuppression, leuconeutropenia, probably related to the ganciclovir treatment, may have contributed to this reactivation in our patient

The diagnosis of toxoplasmic infection is difficult. Indeed, serological changes (rise in baseline antibody titres or the development of antibodies) are frequently lacking in immunocompromised patients. So far, our case is the only one described in a toxoplasma seropositive liver transplant recipient with no increase in antibodies titres, which were regularly measured. This clearly shows that serological data are unreliable in liver transplant recipients, as in other immunocompromised patients.

Disseminated toxoplasmosis is associated with fever and a multivisceral involvement. The organs most often involved are the lungs, heart, and brain. ${ }^{6}$ Visualization of tachyzoites in BAL fluid by Giemsa staining is difficult because of their small size. Immunostaining of tissues dramatically improves toxoplasma detection. $^{7}$ The polymerase chain reaction (PCR) can also be performed on BAL fluid or blood samples. ${ }^{8}$ The use of both morphology and PCR improves the sensitivity of the diagnosis. ${ }^{7}$

D Wendum, N Carbonell, M Surcek, O Chazouillères, J-F Fléjou

Departments of Pathology and Hepatology, Hôpital Saint-Antoine, AP-HP, 184 Rue du Faubourg Saint-Antoine, 75571 Paris Cedex 12, France dominique.wendum@sat.ap-hop-paris.fr

\section{References}

1 Lucet JC, Bailly MP, Bedos JP, et al. Septic shock due to toxoplasmosis in patients infected with the human immunodeficiency virus. Chest 1993;104:1054-8.

2 Anthony CW. Disseminated toxoplasmosis in a liver transplant patient. J Am Med Wom Assoc 1972;27:601-3.

3 Jacobs F, Depierreux M, Goldman M, et al. Role of bronchoalveolar lavage in diagnosis of disseminated toxoplasmosis. Rev Infect Dis 1991;13:637-41.

4 Mayes JT, O'Connor BJ, Avery R, et al. Transmission of Toxoplasma gondii infection by liver transplantation. Clin Infect Dis 1995;21:511-15.

5 Lappalainen M, Jokiranta TS, Halme L, et al. Disseminated toxoplasmosis after liver transplantation: case report and review. Clin Infect Dis 1998:27:1327-8.

6 Gleason TH, Hamlin WB. Disseminated toxoplasmosis in the compromised host. A report of five cases. Arch Intern Med 1974; 134:1059-62.

7 Held TK, Kruger D, Switala AR, et al. Diagnosis of toxoplasmosis in bone marrow transplant recipients: comparison of PCR-based results and immunohistochemistry. Bone Marrow Transplant 2000;25: 1257-62.

8 Khalifa Ke-S, Roth A, Roth B, et al. Value of PCR for evaluating occurrence of parasitemia in immunocompromised patients with cerebral and extracerebral toxoplasmosis. J Clin Microbiol 1994;32:2813-19.

\section{Incidence and prognostic significance of hypercalcaemia in B-cell non-Hodgkin's lymphoma}

Hypercalcaemia is considered to be rare in B-cell non-Hodgkin's lymphoma (B-NHL). ${ }^{1}$ In this letter I report eight cases with this complication among 112 patients $(7.1 \%)$ diagnosed with B-NHL over a period of five years. The diagnosis of B-NHL was established by morphology and immunohistochemistry of biopsy specimens, and staging was done by computed tomography scan of the chest and abdomen, together with bone marrow aspirate and trephine biopsy. There were 70 patients with high grade B-NHL, 52 of whom had advanced disease (stage III/IV). The remaining 42 had low grade B-NHL.

Five patients with high grade B-NHL presented with hypercalcaemia and another patient developed hypercalcaemia at the time of relapse. One patient with low grade B-NHL developed hypercalcaemia at the time of transformation to Richter's syndrome. One other patient with low grade B-NHL developed hypercalcaemia at the time of relapse All patients had advanced disease. Table 1 shows the details of the patients.

Median survival of the five patients with high grade B-NHL presenting with hypercalcaemia was 10 months. This was significantly shorter than the 47 other patients with advanced disease $(21$ months; $\mathrm{p}<0.05)$ who did not present with hypercalcaemia. The median survival of all eight patients from the time of developing hypercalcaemia was only nine months.

All five patients (cases 1-5) presenting with hypercalcaemia initially responded to rehydration and pamidronate $90 \mathrm{mg}$ intravenously, with normalisation of the serum 
Table 1 Details of the clinical and laboratory findings of the patients with hypercalcaemia and non-Hodgkin's lymphoma (NHL)

\begin{tabular}{|c|c|c|c|c|c|c|c|c|}
\hline Case & $\begin{array}{l}\text { Age/ } \\
\text { Sex }\end{array}$ & $\begin{array}{l}\text { Type of } \mathrm{NHL} \text { and stage } \\
\text { at diagnosis }\end{array}$ & $\begin{array}{l}\text { Time (months) from } \\
\text { diagnosis to } \\
\text { hypercalcaemia }\end{array}$ & $\begin{array}{l}\text { Highest } \\
\text { calcium value } \\
\text { (mmol/l) }\end{array}$ & $\begin{array}{l}\text { Recurrence of } \\
\text { hypercalcaemia }\end{array}$ & Treatment & Response & $\begin{array}{l}\text { Survival } \\
\text { (months) from } \\
\text { developing } \\
\text { hypercalcaemia }\end{array}$ \\
\hline \multirow[t]{2}{*}{1} & $51 / M$ & DLB & At diagnosis & 3.08 & Recurred terminally & CIDEBOM & NR & 11 \\
\hline & & IIIB & & & & DXR & NR & \\
\hline \multirow[t]{2}{*}{2} & $23 / M$ & DLBC & At diagnosis & 4.05 & No recurrence & $\mathrm{CHOP}$ & $\begin{array}{l}\mathrm{PR} \text {, early } \\
\text { relapse }\end{array}$ & 10 \\
\hline & & IVB & & & & & & \\
\hline \multirow[t]{2}{*}{3} & $71 / F$ & HGGM & At diagnosis & 4.16 & Recurrent & $\mathrm{CHOP}$ & PR & 10 \\
\hline & & IVB & & & & DXR & NR & \\
\hline \multirow[t]{2}{*}{4} & $70 / F$ & DLBC & At diagnosis & 2.96 & No recurrence & $\mathrm{ClOP}$ & NR & 9 \\
\hline & & IIIB & & & & Mini-BEAM & PR & \\
\hline 5 & $61 / F$ & $\begin{array}{l}\text { HGGM } \\
\text { IVB }\end{array}$ & At diagnosis & 2.92 & No recurrence & $\mathrm{ClOP}$ & PR & 9 \\
\hline \multirow[t]{3}{*}{6} & $57 / M$ & DLBC & 24 , at relapse & 3.16 & Recurred terminally & $\mathrm{ClOP}$ & CR & 5 \\
\hline & & IIIB & & & & Mini-BEAM & PR & \\
\hline & & IVB at relapse & & & & & & \\
\hline \multirow[t]{3}{*}{7} & $65 / F$ & FCC & $\begin{array}{l}49, \text { at the time of } \\
\text { transformation }\end{array}$ & 3.02 & $\begin{array}{l}\text { No response to } \\
\text { treatment }\end{array}$ & Chlorambucil & PR & 2 \\
\hline & & IVB & & & & Mini-BEAM & NR & \\
\hline & & DLBC at transformation & & & & & & \\
\hline \multirow[t]{2}{*}{8} & $74 / M$ & FCC & 15 , at relapse & 3.27 & Recurred terminally & Chlorambucil & PR & 9 \\
\hline & & IVA & & & & $\mathrm{CHOP}$ & PR & \\
\hline
\end{tabular}

Normal calcium range, 2.2-2.6 mmol/I. Type of B-NHL: DLBC, diffuse large B cell; HGGM, high grade gastric maltoma; FCC, follicular centre cell. Chemotherapy protocols: $C$, cyclophosphamide; I, idarubicin; $D$, dexamethasone, $E$, etoposide; $B$, bleomycine; $O$, vincristine; $M$, methotrexate in $B O M$, melphalan in mini-BEAM; $H$, doxorubicin; $\mathrm{P}$, prednisolone; $A$, ARA-C; DXR, radiotherapy. Response: CR, complete response; NR, no response; PR, partial response.

calcium concentration. Parathyroid hormone was undetectable in one patient and low normal in the other four. None of the patients had a paraprotein in the serum or urine or had bone marrow plasmacytosis. No lytic bone lesions were seen on skeletal survey. Once the diagnosis of B-NHL was established they were treated with standard chemotherapy protocols. None of these five patients achieved complete remission with the standard protocol or with further intensive chemotherapy and/or radiotherapy. During the course of the disease one patient had recurrent hypercalcaemia and required intravenous infusion of pamidronate on four occasions.

One patient (case 6) with high grade B-NHL presented in stage IIIB and achieved complete remission with standard chemotherapy. He relapsed after 24 months in stage IVB with bone marrow involvement and hypercalcaemia. There was no plasmacytosis in the bone marrow and no paraprotein was detected. He was treated with intravenous pamidronate infusion with normalisation of serum calcium concentration. He showed only a partial response to intensive chemotherapy. Hypercalcaemia recurred terminally.

None of the 42 patients with low grade B-NHL presented with hypercalcaemia. One of these patients (case 7) transformed to high grade lymphoma (Richter's syndrome) after 49 months. She presented initially with generalised lymphadenopathy and bone marrow involvement and achieved partial remission with chlorambucil. Her disease relapsed after 24 months but she again achieved partial remission with the same drug. She developed hypercalcaemia at the time of transformation. Hypercalcaemia did not respond to repeated intravenous infusion of pamidronate. Her disease showed no response to intensive chemotherapy and she died within two months.

The last patient (case 8) of this series presented with low grade B-NHL in stage IVA with bone marrow involvement. He was initially treated with chlorambucil and achieved partial remission. His disease relapsed after 15 months with hypercalcaemia.
Repeat biopsy showed no change of the histological type and serum parathyroid hormone was low normal. Hypercalcaemia responded to intravenous pamidronate $90 \mathrm{mg}$ and he achieved partial remission with CHOP. How ever, the remission lasted for only three months and both lymphadenopathy and hypercalcaemia recurred. He died of chest infection shortly afterwards. None of the eight patients had renal failure at the time of developing hypercalcaemia, although three of them developed renal impairment in the terminal stages of their disease.

Hypercalcaemia is supposed to be rare in B-NHL but several individual case reports have appeared over the years..$^{2-5}$ No systematic study of hypercalcaemia in B-NHL has been published. Firkin and co-workers ${ }^{2}$ reported an $8.5 \%$ incidence of hypercalcaemia in newly diagnosed patients with high grade B-NHL. This incidence was similar to the present study $(7 \%)$. Some patients in other reports ${ }^{4}$ showed radiological evidence of bone destruction but none of the patients in the present series had this feature.

Transformation of low grade lymphoma into high grade (Richter's syndrome) is a rare and usually terminal complication. Hypercalcaemia has been reported previously in only one patient with Richter's syndrome. ${ }^{6}$ The patient reported here showed total resistance to bisphosphonate treatment for hypercalcaemia, in addition to no response to intensive chemotherapy. This is not unusual for Richter's syndrome and this patient died within a short period.

Hypercalcaemia appears to be rare in low grade B-NHL. None of the patients in the present series presented with this complication and only one patient with follicular centre cell lymphoma developed hypercalcaemia during the course of the disease. There appear to be no other reported cases of hypercalcaemia in patients with follicular centre cell lymphoma, although it has been reported in some patients with Waldenstrom's macroglobulinaemia (lymphoplasmacytic lymphoma), another subtype of low grade B-NHL. ${ }^{4}$
The cause of hypercalcaemia in B-NHL appears to be humoral. A raised concentration of parathyroid hormone related protein was found in some patients but not in all. ${ }^{3}$ A close correlation between the concentration of this protein and hypercalcaemia was also found in some patients, which strongly suggests a causal role. ${ }^{2}$ The importance of the other humoral mediators of bone resorption, such as tumour necrosis factor $\alpha$ and interleukin 6, is conjectural. ${ }^{6}$

Hypercalcaemia is usually associated with a poor prognosis in malignant diseases. ${ }^{1} \mathrm{~B}-\mathrm{NHL}$ appears to be no exception. It is concluded that hypercalcaemia is not rare in B-NHL, particularly in the high grade type, and carries a poor prognosis.

G Majumdar

Doncaster Royal Infirmary, Thorne Road, Doncaster DN2 5LT, UK; gautam.majumdar@dbh.nhs.uk

\section{References}

Shad AT. Complications in the management of non-Hodgkin's lymphomas. In: Magrath I, ed. The non-Hodgkin's lymphomas, 2 nd ed. Arnold, 1997:597-629.

2 Firkin F, Seymour JF, Watson A, et al. Parathyroid hormone-related protein in hypercalcaemia associated with haematological malignancy. Br J Haematol 1996;94:486-92.

3 Wada S, Kitamura H, Matsuura Y, et al. Parathyroid hormone-related protein as a cause of hypercalcemia in B-cell type malignant lymphoma. Intern Med 1992;31:968-72.

4 Rossi J F, Bataille R, Chappard D, et al. B cell malignancies presenting with unusual bone involvement and mimicking multiple myeloma. Study of nine cases. Am J Med 1987:83:10-16.

5 Lobato-Mendizabal E, Ruiz-Arguelles GJ, Ruiz-Arguelles A, et al. Hypercalcemia and osteolytic lesions associated with pre-B-cell primary lymphoma of the bone marrow. Rev Invest Clin 1990;42:226-30.

6 Beaudreuil J, Lortholary O, Martin A, et al. Hypercalcemia may indicate Richter's syndrome. Cancer 1997;79:1211-15. 


\section{Paraffin wax embedded muscle is suitable for the diagnosis of muscular dystrophy}

The article by Sheriff et al on the use of paraffin wax embedded muscle for the diagnosis of muscular dystrophy ${ }^{1}$ illustrates some valid points, but some are questionable. Excellent results are illustrated and some retrospective studies of archival material will clearly be possible.

However, many of us in the field of muscle pathology will be alarmed at the statement in the discussion that "...frozen muscle tissue is no longer necessary for the diagnosis of muscular dystrophy, with the exception of LGMD2F". This statement is premature, inaccurate, and only deals with a limited number of muscular dystrophies. It also takes no account of the fact that the type of neuromuscular disorder is not known before a biopsy is taken, so tissue must be prepared for all possible studies.

Enzyme histochemistry still has an important role, and requires frozen tissue. ${ }^{2}$ The authors take no account of the importance of immunoblotting, which requires frozen tissue, and that some defective proteins can only be studied on immunoblots (for example, calpain 3, responsible for limb girdle muscular dystrophy $2 \mathrm{~A}$ ).

No evidence of the diagnostic use of the technique is shown; only the known localisation of antibodies in control muscle. No assessment of reduced or partial protein expression is shown although this, in contrast to absent protein, occurs in many muscular dystrophies. It is essential that reduced expression is fully assessed in fixed material before frozen material is dispensed with.

Secondary abnormalities are also useful ${ }^{3}$ and the value of paraffin wax sections for the assessment of these is not known, or not possible. For example, the commercial antibodies to fetal myosin (Novocastra MHCn) and to laminin $\beta 1$ (Chemicon) produce negative results with antigen retrieval, but both are important in muscular dystrophies. ${ }^{3}$

The figures illustrate excellent morphology of paraffin wax embedded material. However, fig $\mathrm{lG}, \mathrm{H}$ shows rounded fibres that may be pathological or artefact; in frozen muscle of dystrophic muscle this is an important pathological feature. In addition, it is well known that wax embedding can cause unacceptable artefacts, and results differ from sample to sample and from laboratory to laboratory.

The number of gene defects responsible for a muscular dystrophy is increasing rapidly. It is not possible to know the type of material that will be required in the future, but a bank of frozen muscle will probably be the most versatile. Contrary to the comments on page 520 , adequate freezing, storage, and orientation of frozen material are all possible with care, and fixed frozen sections give equivalent morphology of inflammatory cells.

It has taken decades to ensure that muscle samples are kept out of formalin so that a wide range of techniques can be applied. The role of antigen retrieval will probably increase, but the stage when everything, both now and in the future, can be performed on paraffin wax embedded material has not yet been reached. I hope all clinicians and muscle pathologists will take note of this and not set the clock back.

C A Sewry

Department of Histopathology, Robert Jones and Agnes Hunt Orthopaedic Hospital, Oswestry SY107AG, UK; c.sewry@ic.ac.uk

\section{References}

Sheriffs IN, Rampling D, Smith VV. Paraffin wax embedded muscle is suitable for the diagnosis of muscular dystrophy. J Clin Patho 2001;54:517-20.

2 Sewry CA, Dubowitz V. Histochemistry and immunocytochemistry of muscle in health and disease. In: Hilton Jones D, Karpati G, eds. Disorders of voluntary muscle, 7th ed. Cambridge: Cambridge University Press, 2001:251-82.

3 Sewry C. Immunocytochemical analysis of human muscular dystrophy. Microsc Res Tech 2000;8: 142-54.

4 Sewry CA, Qui L. Immunological reagents and amplification systems. In: Bushby K Anderson LVB, eds. Methods in molecular medicine-the muscular dystrophies. Totowa: Humana Press, 2001:325-38

5 Brown SC, Muntoni F, Sewry CA.

Non-sarcolemmal muscular dystrophies. Brain Pathol 2001;11:193-205.

\section{Authors' reply}

The purpose of our article was not to belittle the value of frozen material in the advance ment of muscle pathology diagnosis (that is, for western blotting), but to stress that we should not ignore humble paraffin wax embedded sections. It is vital to emphasise that with the help of immunohistochemistry they facilitate the accurate diagnosis of many muscular dystrophies and other muscle pathologies, such as nemalin myopathy.

Dr Sewry's comment about negative results for laminin $\beta 1$ and fetal myosin on paraffin wax embedded sections is currently valid, but antigen retrieval techniques are evolving and new antibodies are being developed, allowing larger antibody panels to be used on paraffin wax embedded tissue.

The question of the ease of interpretation of paraffin wax embedded versus frozen tissue is partly a matter of re-education. Adequate freezing, storage, and orientation of frozen material is no problem in specialist centres; however, referred frozen tissue from centre unaccustomed to dealing with them is often inadequate, and in those situations paraffin wax embedded tissue can provide the diagnosis. Moreover, there is an opportunity to study archival tissue or tissue taken at necropsy when there has been no clinical suspicion of muscle disease.

We are not turning back the clock, merely suggesting that much can be achieved using routinely processed tissue. In an ideal world, any tissue should be preserved for many different techniques (morphological, enzyme, protein, DNA, and RNA analyses). However, we live in a world with constraints. Given a choice of badly frozen/partially thawed mus cle or paraffin wax embedded sections for morphological interpretation (with the help of immunohistochemistry) the latter is more likely to be helpful.

I N Sheriffs, D Rampling, V V Smith

Department of Histopathology, Camelia Botnar Laboratories, Great Ormond Street Hospital for Sick Children NHS Trust, Great Ormond Street, London WCIN 3JH, UK; V.Smith@ich.ucl.ac.uk

\section{Skin tags and the atherogenic lipid profile}

I read the short report by MA Crook on "Skin tags and the atherogenic lipid profile" ${ }^{\prime 1}$ with interest. Multiple skin tags are frequently found in patients with acromegaly and may predict colonic polyps. ${ }^{2}$ Hypersecretion of growth hormone induces insulin resistance, with glucose intolerance occurring in 29-45\% and clinical diabetes mellitus in $10-20 \%$ of cases. Hypertriglyceridaemia occurs in 19$44 \%$ of patients with acromegaly and is probably the result of decreased hepatic triglyceride lipase and lipoprotein lipase activities ${ }^{3}$ because the activities of these enzymes rise after successful lowering of growth hormone values. Could increased growth hormone concentrations be the link between skin tags, insulin resistance, and the atherogenic lipid profile in these four cases?

P Twomey

Clinical Biochemistry, Royal Infirmary, Edinburgh EH3 9YW, UK; P.Twomey@ed.ac.uk

\section{References}

1 Crook MA. Skin tags and the atherogenic lipid profile J Clin Pathol 2000:53:873-4.

2 Leavitt J, Klein I, Kendricks F, et al. Skin tags: a cutaneous marker for colonic polyps. Ann Intern Med 1983;98:928-30.

3 Murase T, Yamada N, Ohsawa N, et al. Decline of postheparin plasma lipoprotein lipase in acromegalic patients. Metabolism 1980;29:666-772.

\section{Author's reply}

I was very interested in Dr Twomey's letter suggesting that growth hormone may be a possible link between skin tags and the atherogenic lipid profile. Unfortunately, we do not have growth hormone determinations in our patients so we are unable to test his hypothesis, although presumably it would not be too difficult to design such studies. The cutaneous manifestations of lipid disorders are relatively unexplained and unexplored Why-for example, do xanthelasma or eruptive xanthoma appear at certain sites and not in every patient with lipid abnormalities? Interestingly, one of the patients in our study who had an atherogenic lipid profile also manifested bilateral ear lobe creases. The importance of this is unclear and also merits further study, particularly because these are thought to be associated with cardiovascular disease. ${ }^{1-3}$

Department of Chemical Pathology, 5th Floo Tower, Guy's Hospital, London SEl 9RT, UK martin.crook@gstt.sthames.nhs.uk

\section{References}

1 Doering C, Ruhsenberger C, Phillips DS. Ear obe creases and heart disease. J Am Geriatr Soc 1977;25: 183-5.

2 Moraes D, McCormack P, Tyrrell J, et al. Ear lobe creases and coronary heart disease. Irish Med J 1992:85:131-2.

3 Elliot WJ, Powell LH. Diagonal earlobe creases and prognosis in patients with suspected coronary artery disease. Am J Med 1996;100:205-11.

\section{The role and histological classification of needle core biopsy in conjunction with fine needle aspiration cytology in the preoperative assessment of impalpable breast lesions}

I read with interest the article on the role and histological classification of needle core biopsy (NCB) in conjunction with fine needle aspiration cytology (FNAC) in the preoperative assessment of impalpable breast lesions by Ibrahim et al in the February 2001 edition of the journal. ${ }^{1}$

These findings are at variance with the published literature. My own research on 
FNAC of impalpable breast lesions was non-diagnostic (no epithelial cells) in $14 \%$ of cases. When this was combined with imaging (ultrasound) all of the non-diagnostic cases were resolved, with $70 \%$ showing no change on follow up, $17 \%$ producing benign histology, and $13 \%$ yielding a malignant outcome. ${ }^{2}$ The inadequacy rate, sensitivity, and positive predictive value for the symptomatic lesions were $4 \%, 92.2 \%$, and $100 \%$, respectively. ${ }^{3}$

In a further study, I compared FNAC cytology with NBC at several anatomical sites, including the breast. NCB was only marginally better, occasionally offering additional information. This slight advantage resulted from the availability of tissue from the first and often the only pass for assessment of architecture and the performance of ancillary tests. ${ }^{4}$

The main reasons for the abandonment of FNAC in favour of NCB in the preoperative management of patients with breast lesions are failure of the aspirator to produce diagnostic material and unfamiliarity of the interpreter with the subtleties of breast FNAC.

I believe that by taking an active role with on site management of the FNAC material and discussion with radiological colleagues, the cytopathologist could offer an FNAC service comparable to surgical pathology in sensitivity and very similar to frozen sections in specificity.

FNAC is cost effective, with consistent results in experienced hands; sensitive, with relatively few false negative results; and highly specific.

I M Zardawi Mayne Health, Newcastle Laboratory, PO Box 801, Newcastle, New South Wales, Australia; zardawi@hotmail.com

\section{References}

1 Ibrahim AEK, Bateman AC, Theaker LM, et al. The role and histological classification of needle core biopsy in conjunction with fine needle aspiration cytology in the preoperative assessment of impalpable breast lesions. J Clin Pathol 2001;54:121-5.

2 Zardawi IM, Hearnden F, Meyer P, et al. Ultrasound-guided fine needle aspiration cytology of impalpable breast lesions in a rural setting. Acta Cytol 1999;43:163-8.
3 Zardawi IM. Fine needle aspiration cytology in a rural setting. Acta Cytol 1998;42:899-906.

4 Zardawi IM. Fine needle aspiration cytology vs. core biopsy in a rural setting. Acta Cytol 1998;42:883-7.

\section{CSF spectrophotometry in the diagnosis of subarachnoid haemorrhage}

The recent "Best Practice" article by Dr Cruickshank ${ }^{1}$ does not mention pseudoxanthochromia caused by contamination of the cerebrospinal fluid (CSF) with iodine solution at the time of sample collection. The problem seems to occur when iodine solution is applied to the patient's skin and the operator's glove and then the specimen is contaminated. When combined with a traumatic tap in a normal patient, this technique can mimic the appearance of subarachnoid haemorrhage. Clues to the presence of pseudoxanthochromia are iodine staining around the outside of the specimen container, and the absorbance maximum of iodine is typically $445 \mathrm{~nm}$ compared with bilirubin at $450-460 \mathrm{~nm}$ Preparation of the skin with chlorhexidine instead of iodine avoids this source of potential confusion.

S A lversen

Brighton Healthcare NHS Trust, Eastern Road, Brighton BN2 5BE, UK Andrew.versen@bsuh.nhs.uk

\section{Reference}

1 Cruickshank AM. Best Practice No 166. CSF spectrophotometry in the diagnosis of subarachnoid haemorrhage. J Clin Pathol 2001:54:827-30.

\section{Another case of mantle cell lymphoma presenting as breast masses}

We read with great interest the recently published article by Windrum et al about a mantle cell lymphoma presenting as a breast mass. ${ }^{1} \mathrm{~A}$ separate case of mantle cell lymphoma involving both breasts was also reported last year.
We wish to report the third case of a mantle cell lymphoma involving the breast, in this case presenting as bilateral breast masses. The patient is a 77 year old woman whose bilateral masses were palpated on routine physical examination. Core biopsies were performed and the biopsied tissues were processed routinely in our laboratory. All microscopic patterns were identical bilaterally. The entirety of the specimen consisted of a diffuse monomorphic population of small lymphocytes. Adipose tissue or residual ductal units were not identified. The immunohistochemical profile of the tumour was evaluated on $4 \mu \mathrm{m}$ thick, dewaxed sections using the standard streptavidin-biotin immunoperoxidase technique with diaminobenzidine as chromogen. The cells were strongly positive for CD5 (clone 54/F6; dilution, 1/80; Dako, Carpinteria, California, USA), cyclin Dl (clone AB-1; dilution, 1/100; Neomarkers, Fremont, California, USA), and bcl-2 (monoclonal; dilution, 1/40; Dako), but were negative for CD23 (clone MHM-6; dilution, 1/100; Dako). We interpreted this immunophenotypic profile as being most consistent with mantle cell lymphoma. Several types of lymphoma have been reported in the breast, with diffuse large $\mathrm{B}$ cell non-Hodgkin's lymphoma being the most common. ${ }^{3}$ These three cases show that mantle cell lymphoma should be included in that differential diagnosis.

O Fadare, P Shukla

Department of Pathology, Yale-New Haven Hospital/Yale University School of Medicine, 20 York Street, East Pavilion 2-631, New Haven, CT 06504, USA; Oluwole.fadare@yale.edu

\section{Refernces}

1 Windrum P, Morris TCM, Catherwood MA, et al. Mantle cell lymphoma presenting as a breast mass. J Clin Pathol 2001;54:883-6.

2 Boullanger N, Renou P, Dugay J, et al. Palpable mantle cell lymphoma in the breast. Presse Med 2001;30:163-5.

3 Topalovski M, Crisan D, Mattson JC. Lymphoma of the breast: a clinicopathologic study of primary and secondary cases. Arch Pathol Lab Med 1999;123:1208-18. 